\title{
Interpreting Velocities from Heat-Based Flow Sensors by Numerical Simulation
}

\author{
Grace W. Su${ }^{1}$, Barry M. Freifeld ${ }^{1}$, Curtis M. Oldenburg ${ }^{1}$, Preston D. Jordan ${ }^{1}$, and Paul.F. Daley ${ }^{2}$ \\ ${ }^{1}$ Earth Sciences Division \\ Lawrence Berkeley National Laboratory \\ University of California \\ Berkeley, CA 94720 \\ ${ }^{2}$ Energy and Environment Directorate \\ Lawrence Livermore National Laboratory \\ Livermore, CA 94550
}

July 19, 2005 


\section{Abstract}

We have carried out numerical simulations of three-dimensional non-isothermal flow around an in situ heat-based flow sensor to investigate how formation heterogeneities can affect the interpretation of ground water flow velocities from this instrument. The flow sensor operates by constant heating of a $0.75 \mathrm{~m}$ long, $5 \mathrm{~cm}$ diameter cylindrical probe, which contains 30 thermistors in contact with the formation. The temperature evolution at each thermistor can be inverted to obtain an estimate of the ground water flow velocity vector using the standard interpretive method, which assumes that the formation is homogeneous. Analysis of data from heat-based flow sensors installed in a sand aquifer at the Former Fort Ord Army Base near Monterey, California suggested an unexpected component of downward flow. The magnitudes of the vertical velocities were expected to be much less than the horizontal velocities at this site because the sensors were installed just above a clay aquitard. Numerical simulations were conducted to examine how differences in thermal conductivities may lead to spurious indications of vertical flow velocities. We found that a decrease in the thermal conductivity near the bottom of the sensor can perturb the temperature profiles along the instrument in such a manner that analyses assuming homogeneous thermal conductivity could indicate a vertical flow component even though flow is actually horizontal. This work demonstrates how modeling can be used to simulate instrument response to formation heterogeneity, and shows that caution must be used in interpreting data from such devices using overly simplistic assumptions. 


\section{Introduction}

Accurate estimates of ground water flow velocities are essential for a number of applications, including site characterization and monitoring, ground water remediation, and water resources management. A number of technologies exist to measure ground water flow velocities, e.g., the colloidal borescope (Kearl and Case, 1992; Kearl and Roemer, 1998), the horizontal heat-pulse flowmeter (Hess, 1986; Young et al, 1991; Molz and Young, 1993), the acoustic doppler velocimeter (SonTek, 1996), and fluid flow electrical conductivity logging (Tsang, et al, 1990; Pedler et al., 1992; Tsang and Doughty, 2003). A comparison of these technologies for measuring horizontal ground water flow is detailed in Wilson et al. (1999). All of these techniques require measurements to be made in the screened interval of a borehole and only provide a snapshot in time of the flow velocities.

Ten years ago, Hydrotechnics, Inc. ${ }^{\circledR}$ (Albuquerque, NM) introduced an in situ heat-based flow sensor that is emplaced within the formation by a hollow-stem auger and provides a continuous record of the horizontal and vertical Darcy magnitudes and directions (Ballard, 1996). The flow sensor is a cylinder with a diameter of $0.05 \mathrm{~m}$ and a length of $0.75 \mathrm{~m}$ with a surface heater that dissipates up to 100 watts of heat uniformly over a length of $0.65 \mathrm{~m}$ (Ballard, 1996). Ground water flowing past the instrument carries heat energy around the tool, cooling the upstream side, and warming the downstream side. Any vertical component of ground water flow similarly shifts the center of the surface temperature profile away from the physical center of the tool. An array of 30 thermistors located on the surface of the flow sensor records the temperature field of the surrounding water-saturated formation that has collapsed around the instrument during 
installation. In standard analysis, the temperature evolution at each thermistor is inverted to obtain an estimate of the ground water flow velocity vector (i.e., horizontal and vertical components, and azimuth) assuming that the formation is thermally and hydraulically homogeneous and of infinite extent. The best fit values for the ground water flow velocity vector are obtained by minimizing the difference between the measured temperatures from the sensor with the temperature distribution predicted by an analytical expression derived by Romero (1995).

Heterogeneities in the formation properties around an in situ heat-based flow sensor may lead to incorrect interpretations of the flow velocities. Ballard et al. (1996) reported estimates of large downward flow velocities from heat-based flow sensors at their study site in South Carolina, and they suggested that vertical conduits of relatively high hydraulic conductivity created when the flow sensors were installed could be responsible for the high vertical velocities. Our experiences with heat-based flow sensors installed at the former Fort Ord Army Base near Monterey, California, suggest that differences in the thermal properties of the formation around the flow sensor may also lead to incorrect velocity estimates from these sensors. Three heat-based flow sensors were installed in an area of Fort Ord called Operational Unit 1 (OU 1), which is comprised of an unconfined aquifer containing fine- to medium-grained, well-sorted dune sands and an underlying low-permeability clay layer (Oldenburg et al., 2002). The magnitudes of the vertical components of velocity were expected to be much less than the horizontal components at this site because of the underlying clay aquitard. However, the vertical and horizontal components of velocity estimated using the flow sensors and the standard homogeneous data analysis were about the same magnitude, and in one case, the vertical component was ten times 
larger than the estimated horizontal velocities. The flow sensors at Fort Ord were installed just above the clay layer, which has a lower thermal conductivity and permeability than the overlying sand and may distort the temperature field around the flow sensor.

In this paper, we demonstrate how sophisticated numerical modeling can be used to simulate instrument response to formation heterogeneity using the heat-based flow sensor as the example instrument. Three-dimensional non-isothermal numerical simulations are conducted to investigate how differences in the thermal conductivities around a heat-based flow sensor may lead to temperature profiles that would suggest apparent downward flow if the standard, homogeneous data analysis is used. Although the example instrument and corresponding simulations are specific to the heat-based flow sensor and OU 1, the approach involving threedimensional numerical simulations to test a hypothesis about the origin of a suspicious interpreted result (e.g, large vertical ground water flow) is applicable to other field measurements and serves to test the conditions under which simpler analysis approaches are valid.

\section{Horizontal and Vertical Flow at Fort Ord}

The horizontal and vertical components of ground water flow estimated at Fort Ord using the flow sensors and homogeneous data analysis are summarized in Table 1. Data are shown for three flow sensors: OU1-36, OU1-37, and OU1-39. Although nearly continuous data from the flow sensors have been collected since January 2001, the results presented in the table are from mid-2003 and are representative of the relative magnitudes of the estimated horizontal and vertical components of Darcy velocity. In OU1-36, the horizontal component of flow estimated 
from the flow sensor data was nearly an order of magnitude less than the vertical component, while the horizontal components in OU1-37 and OU1-39 were nearly the same as the vertical ones. These results raised questions because the vertical ground-water flow is expected to be much less than the horizontal flow because of the underlying low-permeability clay layer.

Table 1 also presents the horizontal Darcy velocities calculated for mid-2003 using the average hydraulic conductivity of $1.8 \times 10^{-5} \mathrm{~m} / \mathrm{s}$ (permeability of $1.8 \times 10^{-12} \mathrm{~m}^{2}$ at $20^{\circ} \mathrm{C}$ ) estimated from pumping tests (Oldenburg et al., 2002) and the horizontal hydraulic gradients estimated from contoured water levels obtained from a network of monitoring wells in OU 1. The gradients at OU1-36, OU1-37, and OU1-39 range over fourfold, from 0.006 to 0.027 . The calculated Darcy velocities are remarkably similar to the horizontal components of Darcy velocity estimated from the flow sensors, differing by only up to a factor of two. This provides confidence that the flow sensors give reasonable estimates for the horizontal components of velocity. Data to calculate vertical Darcy velocities at Fort Ord were not available.

Vertical profiles of ground-water temperature in observation wells can also provide information on horizontal and vertical ground-water flow (e.g., Bredehoeft and Papadopulus, 1965; Lu and Ge, 1996; Reiter, 2001). Figure 1 contains schematics of ground water temperature profiles under an assumed, upward-directed geothermal gradient that have been perturbed by ground water flow. Downward ground-water flow typically produces a concave upward temperature profile (Figure 1a) because of the cooler shallower water advecting downward, whereas upward flow causes the temperature profile to be convex upward since warmer water from below is advected up (Figure 1b). Horizontal flow that brings cool water can also produce a temperature 
profile that is concave upward (Figure 1a), whereas warm horizontal flow can cause a convex upward temperature profile (Figure 1b). Although it is usually difficult to distinguish between predominantly horizontal and vertical flow from these profiles (Reiter, 2001), a temperature profile that decreases at shallow depths and then increases at greater depths may indicate the importance of cool horizontal flow (Figure 1c). Strictly downward flow cannot lower the temperatures below the coolest temperatures observed at the top of the flow zone (e.g., Mansure and Reiter, 1979). In addition, downward temperature gradients produce buoyant density gradients that counteract vertical flow.

The ambient ground water temperature profiles recorded in March 2004 over a 2.4 - 3.0 m section of the OU1-36 and OU1-39 monitoring wells at Fort Ord are shown in Figure 2. The ambient ground water temperature profile for OU1-37 was not recorded because the probe used to measure temperature could not move around a slight bend near the top of the well. Figure 2 also presents the screened interval of the wells, the location of the flow sensors, and the stratigraphy at the three locations. Although only a shallow portion of the temperature profile was recorded (the profiles were recorded within $1.5 \mathrm{~m}$ of the well bottom), the temperatures in this interval decrease with depth, which is similar to the upper portion of the profile shown in Figure 1c. Reiter (2001) estimated a horizontal flow component that was two orders of magnitude larger than the vertical component for a profile similar to Figure 1c. While this type of temperature profile does not completely rule out the possibility of vertical flow, it does suggest that a strong horizontal flow component exists in the aquifer as we would expect based on our understanding of OU 1 hydrology (e.g., Oldenburg, et al., 2002). 


\section{Grid Generation and Model Development}

Three-dimensional simulations were conducted using TOUGH2 (Pruess et al., 1999) to investigate how differences in the thermal conductivities around heat-based flow sensors may lead to inaccurate indications of downward flow. Conformal mapping was used to generate a three-dimensional grid for simulating flow and heat transport near this sensor. The simulation domain generated using conformal mapping is computationally efficient because the grid is highly refined near the region of interest (i.e., the flow sensor) and then coarsens rapidly with increasing distance from the instrument. To generate the grid, a regularly spaced array of nodes in the complex plane, located inside a half circle of radius $r=0.025 \mathrm{~m}$, was mapped into a semiinfinite plane outside the half circle using the mapping $w \rightarrow z^{-1}$, where $w$ is the original node location and $z$ is the new location in the conformally mapped grid. Figure 3 shows the plan view of the grid domain created using this mapping. Because conformal maps are angle preserving, the array of nodes generated follows the orthogonality requirement of the integral finite difference method used in TOUGH2. The semi-infinite domain is then truncated into the bounded triangular shape shown, with a maximum distance of $0.6 \mathrm{~m}$ from the center. The inside of the half circle represents the location of the flow sensor, where heat is generated and no flow is allowed to take place. The region outside of the half circle is the formation where flow occurs. This kind of discretization is very useful for simulating borehole- and probe-based instruments whose response is symmetric and coupled to a much larger region of the formation or aquifer. Since the flow sensors are located below the water table, we use TOUGH2 to model fully saturated non-isothermal ground water flow. 
A 17-layer model was used in all the simulations (Figure 4). The top and bottom layers (layers 1 and 17, respectively) had thicknesses of $0.288 \mathrm{~m}$, layers 2 and 16 had thicknesses of $0.144 \mathrm{~m}$, and the remaining thirteen layers had thicknesses of $0.072 \mathrm{~m}$. The heated portion of the flow sensor was represented by nine layers in the center (layers 5-13). As explained below, horizontal flow was imposed across the domain in all the scenarios except for Case $1 \mathrm{~b}$ where vertical flow was imposed. The porosity and particle density of the sand and clay were the same in all the simulations, 0.3 and $2650 \mathrm{~kg} / \mathrm{m}^{3}$, respectively. The saturated thermal conductivities used in the simulations were 2.0 and $/$ or $2.1 \mathrm{~W} / \mathrm{m}^{\circ} \mathrm{C}$ for the sand and 1.0 or $1.8 \mathrm{~W} / \mathrm{m}^{\circ} \mathrm{C}$ for the clay. These values are within the range of thermal conductivity values measured for these sediment types (van Wijk and de Vries, 1966; de Marsily, 1986).

The simulations were divided into four categories based on the formation property that was (or was not) varied. A summary of the parameters used in the different simulations is presented in Table 2. The permeability in all 17 layers was $2 \times 10^{-12} \mathrm{~m}^{2}$ in the first three simulation cases. In the first category of simulations, the thermal conductivity and permeability in the 17 layers were homogeneous and two simulations were run. In Case 1a, flow is strictly horizontal, whereas in Case 1b, flow is strictly vertical. These two simulations are the "end-member base cases" that will be compared to the remainder of the simulations where formation heterogeneities are introduced and horizontal flow is imposed. In this study, heterogeneity was assumed only in the vertical direction, resulting in a "layer-cake" type stratigraphy.

In the second category of simulations, the thermal conductivity was varied. In Cases 2a and 2b, layers 14 - 17 were assigned thermal conductivities of $1.0 \mathrm{~W} / \mathrm{m}^{\circ} \mathrm{C}$ and $1.8 \mathrm{~W} / \mathrm{m}^{\circ} \mathrm{C}$, respectively, 
while the layers above it had a thermal conductivity of $2.1 \mathrm{~W} / \mathrm{m}^{\circ} \mathrm{C}$. In Case $2 \mathrm{c}$, the thermal conductivity of layers 12 and 13 was set at a slightly lower value of $2.0 \mathrm{~W} / \mathrm{m}^{\circ} \mathrm{C}$ compared to 2.1 $\mathrm{W} / \mathrm{m}^{\circ} \mathrm{C}$ in the remaining layers. The thickness of the sand layer separating the sensor bottom and the top of the clay aquitard was varied in the third category of simulations. A thermal conductivity of $2.1 \mathrm{~W} / \mathrm{m}^{\circ} \mathrm{C}$ was assigned to the appropriate combination of layers 14,15 , and 16 to create a sand layer with a thickness of $0.072 \mathrm{~m}$ (Case 3a), $0.144 \mathrm{~m}$ (Case 3b), or $0.288 \mathrm{~m}$ (Case 3c). A thermal conductivity of $1.0 \mathrm{~W} / \mathrm{m}^{\circ} \mathrm{C}$ was assigned to the clay aquitard below this sand layer. In a fourth category of simulations, the permeability in the lower layers was decreased while the permeability in the upper layers remained at $2 \times 10^{-12} \mathrm{~m}^{2}$. However, permeability variation produced a much smaller effect and in the interest of brevity, these results will not be presented here, but can be found in Su et al. (2005).

Time-invariant pressure boundary conditions were specified along the upstream and downstream boundaries to create horizontal flow across the domain, and on the top and bottom layers of the domain to create vertical flow (Case 1b only). The pressure difference across the domain was selected to produce simulated velocities that were of the same magnitude as the velocities estimated by the flow sensors at Fort Ord (Table 1). The horizontal flow velocity in the simulations was approximately $2.5 \times 10^{-7} \mathrm{~m} / \mathrm{s}$, whereas the vertical flow velocity in Case $1 \mathrm{~b}$ was approximately $-5 \times 10^{-7} \mathrm{~m} / \mathrm{s}$.

Isothermal flow simulations were initially run until steady flow conditions were established. After reaching steady state, 35 watts of heat were applied to the boundary nodes located along the half circles in the nine layers representing the heated portion of the sensor. The rate at which 
heat was applied to each boundary node was proportional to the interface areas of the boundary grid blocks. The heater power used at Fort Ord was approximately 70 watts; 35 watts was used in our simulations since only half of the sensor was modeled.

\section{Results and Discussion}

An "unrolled" two-dimensional plot of the simulated temperature at a radial distance of $0.03 \mathrm{~m}$ is shown in Figure 5 for Case 1a, where flow is horizontal and all the layers are homogeneous. The downstream side of the sensor (azimuth $=0^{\circ}$ ) is shown on the right-hand side of the plot. The center of the sensor is warmer than the top and bottom, and the upstream side $\left(180^{\circ}\right)$ of the sensor is cooler compared to the downstream side $\left(0^{\circ}\right)$ because of horizontal flow across it. The temperature distribution above and below the center of the instrument is nearly symmetric because the thermal conductivity and permeability are the same in all the layers in this simulation. The vertical symmetry of the temperature distribution also indicates that buoyancy flow is negligible.

A shift in the temperature profile along the vertical direction of the flow sensor is interpreted as vertical flow. Therefore, one-dimensional vertical temperature profiles were used to compare the results of the simulations and examine if thermal heterogeneities produced an apparent indication of vertical flow. The temperature profiles on the downstream side of the sensor (azimuth $=0^{\circ}$ ) were plotted as a function of depth. Figure 6 presents plots of the temperature profiles for Cases 1a and 1b, which are the end-member base cases. The temperature profile from Case 1a, where horizontal flow occurs across a homogeneous formation, is nearly symmetric over the nine layers 
representing the heated sensor. In Case 1b, a vertical pressure gradient was applied such that it produced downward flow velocities in the range of the vertical velocities estimated at Fort Ord. As expected, the temperature profile from this simulation is not symmetric, but has higher temperatures at the bottom compared to the top. The general pattern of the temperature profiles produced in Case 1 is consistent with the results from Ballard (1996).

In Cases 2a and 2b, the thermal conductivity of layers 14 - 17 was lowered to 1.0 and 1.8 $\mathrm{W} / \mathrm{m}^{\circ} \mathrm{C}$, respectively, while the thermal conductivity of the remaining layers was $2.1 \mathrm{~W} / \mathrm{m}^{\circ} \mathrm{C}$. These simulations represent the scenario where a clay layer exists immediately below the sensor bottom. Plots of the temperature profiles from these simulations are shown in Figure 7, demonstrating that the temperatures are higher at the bottom of the sensor compared to the top. The temperature difference between the top and bottom of the sensor are $1^{\circ} \mathrm{C}$ and $0.3^{\circ} \mathrm{C}$ when the thermal conductivities of the clay layer are $1.0 \mathrm{~W} / \mathrm{m}^{\circ} \mathrm{C}$ and $1.8 \mathrm{~W} / \mathrm{m}^{\circ} \mathrm{C}$, respectively. Such temperature profiles analyzed assuming homogeneous formation properties would be interpreted as having a downward vertical flow component. The magnitude of the temperature shift from Case $1 \mathrm{~b}$ (strictly vertical flow) was compared to the results of Cases 2a and 2b. The temperature shift in Case $2 \mathrm{~b}$, where the bottom layer had a thermal conductivity of $1.8 \mathrm{~W} / \mathrm{m}^{\circ} \mathrm{C}$, was similar to the shift observed in the vertical flow case. The simulations reveal that a relatively small decrease in the thermal conductivity of the layer immediately below the sensor can alter the temperature profile enough such that it could be interpreted as having a downward flow velocity with a magnitude similar to the ones estimated at Fort Ord. 
The temperature profile from Case 2c, where a thermal conductivity of $2.0 \mathrm{~W} / \mathrm{m}^{\circ} \mathrm{C}$ was assigned to layers 12 and 13 while the thermal conductivity in the remaining layers was $2.1 \mathrm{~W} / \mathrm{m}^{\circ} \mathrm{C}$, is also presented in Figure 7. The small decrease in the thermal conductivity towards the bottom of the sensor was enough to produce a similar temperature shift as observed in the vertical flow case. Therefore, a subtle decrease in the thermal conductivity with depth along the flow sensor with or without the presence of a clay layer below the sensor could also give rise to temperature profiles that when inverted could be interpreted as having a downward flow velocity. Finer textured media has a lower thermal conductivity compared to coarser textured ones (Jury, 1991). If the sand becomes finer with depth, the thermal conductivity could decrease and cause a shift in the temperature profile along the sensor.

At Fort Ord, two of the three flow sensors had a layer of sand separating the bottom of the flow sensor from the top of the clay layer. Simulations were run in Cases 3a - 3c to investigate whether the temperature profile was still altered by the presence of the clay layer when a sand layer separated it from the sensor bottom. With $K_{t, 1}($ sand $)=2.1 \mathrm{~W} / \mathrm{m}^{\circ} \mathrm{C}$ and $K_{t, 2}$ (clay) $=1.0$ $\mathrm{W} / \mathrm{m}^{\circ} \mathrm{C}$, the simulated temperatures are higher towards the bottom when the sand layer is 0.07 $\mathrm{m}$ thick, and then to a much lesser extent when the thickness is $0.144 \mathrm{~m}$, as shown in Figure 8. At a thickness of $0.288 \mathrm{~m}$, the profile is once again nearly symmetric. Therefore, a sand layer with a minimum thickness of around $0.3 \mathrm{~m}$ is necessary to prevent clay-layer properties from altering the temperature profile at the bottom of the sensor. The thicknesses of the sand layer separating two of the sensors from the clay layer at Fort Ord were $0.45 \mathrm{~m}$ and $1.3 \mathrm{~m}$ (OU1-39 and OU1-36, respectively). Based on the simulated results, the thermal conductivity of the clay layer probably had a minimal impact on the temperature profile recorded by these two flow sensors. Even 
though the temperature profiles recorded by these sensors probably were not affected by the underlying clay layer, the measured temperature shift may have occurred because the thermal conductivity of the sand decreased slightly with depth along the length of the flow sensors.

\section{Summary}

This study demonstrated how numerical modeling can be used to simulate instrument response to formation heterogeneity. Three-dimensional, flow and heat transport simulations near an in situ heat-based flow sensor were conducted to investigate possible reasons for spurious vertical flow velocities. The modeling approach involving a highly graded discretization, exploitation of the symmetry of the system, and use of a non-isothermal flow simulator are applicable to modeling other borehole- and probe-based instruments. For the heat-based flow sensor simulated, we found that under conditions of strictly horizontal flow, the temperature profile along the length of the sensor can be perturbed by changes in the thermal conductivity such that standard analysis of the data assuming homogeneous formation properties could result in an interpretation of downward flow. This can occur when the thermal conductivity of the porous media decreases towards the bottom of the sensor, and/or when a layer of lower thermal conductivity soil is located close to the bottom of the flow sensor. A decrease in the permeability towards the bottom of the sensor also can result in temperature profiles that could be interpreted as downward flow, but permeability changes may have a smaller effect on the temperature profiles at Fort Ord compared to changes in thermal conductivity (Su et al., 2005). 
The simulations conducted in this study assumed that the properties only varied vertically. This layer-cake stratigraphy does not account for the three-dimensional structure of the formation (i.e., dune beds). In addition, collapsed material around instruments can be heterogeneous and is often loose and filled with voids. As suggested by Ballard (1996), the characteristics of the collapsed annular fill directly contacting the flow sensor could produce a vertical ground water

flow component. Future work should be conducted to investigate the impact of collapsed fill on producing vertical flow along heat-based flow sensors. The effect of the ratio of the sand-to-clay thermal conductivities relative to the advective component on producing apparent vertical flow velocities should also be investigated in future studies to better interpret data from in situ heatbased flow sensors.

The simulation results demonstrate that the temperature profiles recorded by in situ heat-based flow sensors are sensitive to differences in the thermal conductivities of the sediment and that caution must be used in interpreting data from such devices using overly simplistic assumptions. The vertical velocity estimates obtained from heat-based flow sensors should be evaluated carefully and compared with estimates from other methods if possible, such as using ground water temperature profiles to estimate vertical velocities (e.g., Reiter, 2001) and measuring pressures at different depths to determine if a vertical flow gradient exists.

\section{Acknowledgment}

This work was supported by U.C. Santa Cruz (UCSC) through the U.S. Army Construction Engineering Research Laboratories (US ACERL), and by the U.S. Department of Energy under 
contract No. DE-AC03-76SF00098. The careful review of this manuscript and suggestions for improvement by Christine Doughty, Chin-Fu Tsang, David Stonestrom, Andy Fisher, and an anonymous reviewer are greatly appreciated. We also acknowledge the ongoing support and encouragement from Russ Flegal, Jim Gill, and Andy Fisher (UCSC), and Richard Lampo (US ACERL)

\section{References}

Ballard, S. 1996. The in situ permeable flow sensor: A ground-water flow velocity meter, Ground Water, v. 34, no. 2: 231-240.

Ballard, S., G.T. Barker, and R.L. Nichols. 1996. A test of the in situ permeable flow sensor at Savannah River, SC, Ground Water, v. 34, no. 3: 389-396.

Bredehoeft, J.D. and I.S. Papadopulos. 1965. Rates of vertical ground water movement estimated from the earth's thermal profile, Water Resources Research, 325-328.

de Marsily, G. 1986. Quantitative Hydrogeology: Ground water Hydrology for Engineers, Academic Press, San Diego, CA.

Hess, A.E. 1986. Identifying hydraulically conductive fractures with a slow-velocity borehole flowmeter: Canadian Geotechnical Journal, v. 23, no. 1: 69-78.

Jury, W.A. 1991. Soil Physics, $5^{\text {th }}$ ed, New York: John Wiley and Sons. 
Kearl, P.M., and Case, C.M. 1992. Direct field measurement of ground water velocities: Interdisciplinary Approaches in Hydrology and Hydrogeology, American Institute of Hydrology, p. 91-102.

Kearl, P.M., and Roemer, K. 1998. Evaluation of ground water flow directions in a heterogeneous aquifer using the colloidal borescope: Advances in Environmental Research, v. 2, no. 1: 12-23.

Lu, N. and S. Ge. 1996. Effect of horizontal heat and fluid flow on the vertical temperature distribution in a semiconfining layer, Water Resources Research, v. 32, no. 5: 1449-1453.

Mansure, A.J. and M Reiter. 1979. A vertical ground-water movement correction for heat flow, J. Geophysical Research, vol. 84: 3490-3496.

Molz, F.J., and S.C. Young. 1993. Development and application of borehole flowmeters for environmental assessment, The Log Analyst, v. 34, no. 1: 13-23.

Oldenburg, C.M., P.F. Daley, B.M. Freifeld, J. Hinds, and P.D. Jordan. 2002. Three-dimensional ground water flow, aquifer response, and treatment system monitoring at Site OU1, Former Fort Ord, California, Lawrence Berkeley National Laboratory Report, LBNL49586. 
Pedler, W.H., C.L. Head, and L.L Williams. 1992. Hydrophysical logging-A new wellbore technology for hydrogeologic and contaminant characterization of aquifers, in Proceedings, The Sixth National Outdoor Action Conference on Aquifer Restoration, Ground Water Monitoring, and Geophysical Methods, National Ground Water Association, May 11-13, 1992, Las Vegas, Nev.: p. 701-71.

Pruess, K., C. Oldenburg, and G. Moridis. 1999. TOUGH2 user's guide, Version 2, Lawrence Berkeley National Laboratory Report, LBNL-43134.

Reiter, M. 2001. Using precision temperature logs to estimate horizontal and vertical ground water flow components, Water Resources Research, v. 37, no. 3: 663-674.

Romero, L.A. 1995. Forced convection past a slender body in a saturated porous medium, Journ. Applied Math., v. 55, no. 4.

SonTek, Inc. 1996. Modified ADV for 3D velocity measurements in boreholes-Final project report: U.S. Geological Survey Contract Number 1434-95- C-40232, 29 p.

Su, G.W., B.M. Freifeld, C.M. Oldenburg, P.D. Jordan, and P.F. Daley. 2005. Simulation of insitu permeable flow sensors for measuring groundwater velocity, Lawrence Berkeley National Laboratory Report LBNL-57084. 
Tsang, C.F., P. Hufschmied, and F.V. Hale. 1990. Determination of fracture inflow parameters with a borehole fluid conductivity logging method, Water Resources Research, v. 26, no. 4: $561-578$.

Tsang, C.F. and C. Doughty. 2003. Multirate flowing fluid electric conductivity logging method, Water Resources Research, v. 39, no. 12: 1354, doi:10.1029/2003WR002308.

Van Wijk, W.R. and D.A. de Vries. 1966. The atmosphere and the soil, in van Wijk, W.R., ed., Physics of Plant Environment, $2^{\text {nd }}$ ed. Amsterdam: North-Holland Publishing Co.

Wilson, J. T., W.A. Mandell, F.L. Paillet, E.R. Bayless, R. T. Hanson, P. M. Kearl, W. B. Kerfoot, M.W. Newhouse, and W. H. Pedler. 1999. An Evaluation of Borehole Flowmeters Used to Measure Horizontal Ground-Water Flow in Limestones of Indiana, Kentucky, and Tennessee, U.S. Geological Survey Water-Resources Investigations Report 01-4139.

Young, S.C., H.S. Pearson, G.K. Moore, and R.B. Clapp. 1991. Application of the electromagnetic borehole flowmeter technique at the Oak Ridge Laboratory: Tennessee Valley Authority, Report WR28-1-900-247, Norris, Tenn. 


\begin{tabular}{|c|c|c|c|}
\hline & OU1-36 & OU1-37 & OU1-39 \\
\hline Well screen (m) & $15.5-24.5$ & $18.8-26.4$ & $21.1-28.6$ \\
\hline Flow sensor (m) & $24.8-25.6$ & $26.7-27.5$ & $28.8-29.6$ \\
\hline $\begin{array}{c}\text { Distance from sensor } \\
\text { base to clay (m) }\end{array}$ & 1.3 & 0 & 0.45 \\
\hline $\begin{array}{c}\text { Vertical velocity - } \\
\text { flow sensor, mid-2003 } \\
\text { (m/s) }\end{array}$ & $-1.1 \times 10^{-6}$ & $-4.2 \times 10^{-7}$ & $-3.5 \times 10^{-7}$ \\
\hline $\begin{array}{c}\text { Horizontal velocity - } \\
\text { flow sensor, mid-2003 } \\
\text { (m/s) }\end{array}$ & $1.0 \times 10^{-7}$ & $3.3 \times 10^{-7}$ & $0.6 \times 10^{-7}$ \\
\hline $\begin{array}{c}\text { Horizontal hydraulic } \\
\text { Gradient (2nd quarter } \\
\text { 2003) }\end{array}$ & 0.0058 & 0.0090 & $4.9 \times 10^{-7}$ \\
\hline $\begin{array}{c}\text { Horizontal Darcy } \\
\text { velocity }{ }^{\mathrm{a}} \text { (m/s) }\end{array}$ & $1.0 \times 10^{-7}$ & $1.6 \times 10^{-7}$ & 0.027 \\
\hline
\end{tabular}

${ }^{a}$ Calculated using hydraulic gradient and a hydraulic conductivity of $1.8 \times 10^{-5} \mathrm{~m} / \mathrm{s}$, obtained from pump tests.

Table 1. Summary of horizontal and vertical flow velocities at Fort Ord. 


\begin{tabular}{|c|c|c|c|c|}
\hline \multirow[t]{2}{*}{ Case } & \multirow{2}{*}{$\begin{array}{l}\text { Parameter } \\
\text { changed }\end{array}$} & \multicolumn{2}{|c|}{$\begin{array}{c}\text { Thermal } \\
\text { Conductivity }\left(\mathrm{W} / \mathrm{m}^{\circ} \mathrm{C}\right)\end{array}$} & \multirow{2}{*}{$\begin{array}{c}\text { Sand layer } \\
\text { thickness } \\
\text { between sensor } \\
\text { and clay layer } \\
\text { (m) }\end{array}$} \\
\hline & & $K_{t, 1}$ & $K_{t, 2}$ & \\
\hline $1 \mathrm{a}$ & $\begin{array}{l}\text { no change, } \\
\text { homogeneous }\end{array}$ & 2.1, layers 1-17 & -- & N/A \\
\hline $1 b^{*}$ & $\begin{array}{l}\text { no change, } \\
\text { homogeneous }\end{array}$ & 2.1, layers 1-17 & -- & N/A \\
\hline $2 a$ & $\begin{array}{l}\text { thermal } \\
\text { conductivity }\end{array}$ & 2.1, layers 1-13 & 1.0 , layers $14-17$ & 0 \\
\hline $2 \mathrm{~b}$ & $\begin{array}{l}\text { thermal } \\
\text { conductivity }\end{array}$ & 2.1, layers $1-13$ & 1.8 , layers $14-17$ & 0 \\
\hline $2 c$ & $\begin{array}{l}\text { thermal } \\
\text { conductivity }\end{array}$ & $\begin{array}{c}\text { 2.1, layers 1-11; } \\
14-17\end{array}$ & 2.0, layers $12-13$ & N/A \\
\hline 3a & $\begin{array}{l}\text { distance } \\
\text { between sensor } \\
\text { and clay }\end{array}$ & 2.1, layers 1-14 & 1.0 , layers $15-17$ & 0.072 \\
\hline $3 b$ & $\begin{array}{l}\text { distance } \\
\text { between sensor } \\
\text { and clay }\end{array}$ & 2.1, layers 1-15 & 1.0 , layer $16-17$ & 0.144 \\
\hline $3 c$ & $\begin{array}{l}\text { distance } \\
\text { between sensor } \\
\text { and clay }\end{array}$ & 2.1, layers 1-16 & 1.0, layer 17 & 0.288 \\
\hline
\end{tabular}

Permeability in layers $1-17$ is $2 \times 10^{-12} \mathrm{~m}^{2}$ in Cases $1-3$.

*Vertical flow. Remainder of the simulations were conducted under horizontal flow.

Table 2. Summary of parameters used in the three-dimensional simulations of flow and heat transport around a heat-based flow sensor. 


\section{Figure Captions}

Figure 1. Schematic of ground water temperature profiles with depth that can indicate vertical and/or horizontal ground water flow.

Figure 2. Measured ground water temperature profiles in observation wells OU1-36 and OU1-39 at Fort Ord, and stratigraphy column for wells OU1-36, OU1-37, and OU1-39.

Figure 3. Plan view of the numerical grid generated using conformal mapping of flow and heat transport near an in situ heat-based flow sensor.

Figure 4. Seventeen-layer model used in the simulations.

Figure 5. "Unrolled" temperature distribution with depth for Case 1a at a radial distance of 0.03 m (5 mm from the sensor surface).

Figure 6. Temperature depth profiles along the sensor under horizontal and vertical flow in a homogeneous formation.

Figure 7. Temperature depth profiles with varying thermal conductivities (horizontal flow only).

Figure 8. Temperature depth profiles with a layer of sand between the sensor bottom and top of the clay layer (horizontal flow only). 